\title{
Paliperidone Palmitate-induced Urinary Incontinence: A Case Report
}

\author{
Ersin Hatice Karslıoğlu, Elvan Özalp, Ali Çayköylü \\ Department of Psychiatry, T.C.S.B. Dr. Abdurrahman Yurtaslan Oncology Training and Research Hospital, Ankara, Turkey
}

\begin{abstract}
Urinary incontinence, although rarely reported, is one of the most important adverse effects of antipsychotic medication. It can be an embarrassing, distressing, and potentially treatment-limiting. Several antipsychotics, including both typical and atypical varieties, are known to induce urinary incontinence. Many antipsychotic drugs target the neural pathways controlling continence by binding to receptors of some neurotransmitters such as serotonin, dopamine, acetylcholine, and adrenaline. Pharmacological management of incontinence should be considered if there is a risk of cessation of the antipsychotic therapy or any decline in patients' compliance. Amitriptyline, desmopressin, ephedrine, and anticholinergics such as oxybutynin and trihexyphenidyl are the most frequently used agents to treat incontinence. We think that the frequency of incontinence is higher than reported in the literature, and that follow-up routines should include a form of standardized screening for all possible adverse effects, including incontinence, of any given antipsychotic. In this article, we report a case of urinary incontinence as an adverse effect of paliperidone palmitate use during maintenance therapy in a patient with schizophrenia.
\end{abstract}

KEY WORDS: Antipsychotic agents; Schizophrenia; Paliperidone palmitate; Adverse effects; Urinary incontinence.

\section{INTRODUCTION}

Paliperidone palmitate, a palmitate ester of paliperidone, was developed as a parenteral long-acting (depot) form of the atypical antipsychotic paliperidone. In August 2009, it was approved by the US Food and Drug Administration for acute and maintenance therapy in adult patients with schizophrenia. ${ }^{1)}$ In 2011, the Turkish Ministry of Health approved its use for the same clinical indication. Paliperidone or 9-hydroxyrisperidone is the major active metabolite of risperidone. Its pharmacokinetics and mechanisms of action are thought to be similar to that of risperidone. ${ }^{2-4)}$ Paliperidone acts on dopamine D2 and serotonin 5HT2A receptors as an antagonist, exhibiting a high 5HT2A/D2 affinity ratio, like other atypical agents. ${ }^{5)}$ It also binds and antagonizes the $\alpha 1$ - and $\alpha$ 2-adrenergic receptors and H1-histaminergic receptors, but has almost no affinity for the cholinergic receptors. ${ }^{5-7)}$ The paliperidone palmitate suspension contains nanocrystals that undergo slow dissolution and have a rela-

\footnotetext{
Received: April 2, 2015 / Revised: May 26, 2015

Accepted: May 31, 2015

Address for correspondence: Ersin Hatice Karslioğlu, MD Department of Psychiatry, T.C.S.B. Dr. Abdurrahman Yurtaslan Oncology Training and Research Hospital, Ankara Mehmet Akif Ersoy Mh. 13. Cadde No: 56 Yenimahalle 06200 Ankara, Turkey Tel: +90-312-4340990/6272, Fax: +90-312-4324915 E-mail: ehkarslioglu@gmail.com
}

tively long half-life of 25-49 days, ${ }^{8-10)}$ which has made monthly intramuscular administration of paliperidone possible and greatly increased patients' compliance.

Paliperidone can potentially cause orthostatic hypotension, weight gain, and sedation. However, it has a low propensity to induce anticholinergic adverse effects and cognitive impairment, having no antagonistic activity on the cholinergic receptors. ${ }^{3)}$ Numerous studies have assessed the safety and tolerability of paliperidone palmitate ${ }^{8,1,11-19)}$ and reported that treatment emergent adverse effects (TEAEs), such as insomnia, headache, dizziness, sedation, vomiting, injection site pain, extremity pain, myalgia, and extrapyramidal symptoms, were more frequent in the paliperidone palmitate groups than in the placebo groups. ${ }^{20)}$ Hyperprolactinemia and palpitation have also been described. Although oral paliperidone has been reported to occasionally cause urinary incontinence, ${ }^{21,22)}$ to our knowledge, no report of urinary incontinence possibly linked to monthly paliperidone palmitate treatment has been published to date.

Urinary incontinence is an embarrassing, distressing, and potentially treatment-limiting adverse effect of antipsychotic agents. Untreated urinary incontinence may even lead to total non-compliance in distressed patients. Until date, the etiology and optimal treatment strategies for urinary incontinence have not been established. ${ }^{23)}$

(c) This is an Open-Access article distributed under the terms of the Creative Commons Attribution Non-Commercial License (http://creativecommons.org/licenses/by-nc/4.0) which permits unrestricted non-commercial use, distribution, and reproduction in any medium, provided the original work is properly cited. 
Several conventional antipsychotics have been associated with urinary incontinence, including chlorpromazine, thioridazine, fluphenazine, haloperidol, and pimozide. ${ }^{24-27)}$ A comparative cohort study of patients undergoing atypical antipsychotic treatment reported that approximately one in five adults taking clozapine experience nocturnal enuresis. ${ }^{28)}$ This is higher than the proportion reported for some other atypical antipsychotics such as risperidone, olanzapine, and quetiapine. Furthermore, spontaneous reports of adverse events collected by the yellow-card system in the United Kingdom revealed that urinary incontinence and/or enuresis is associated with all of the above-mentioned three antipsychotics, with the highest proportion for risperidone, followed by olanzapine, clozapine, and quetiapine, in this order. ${ }^{29)}$ Though rare, urinary incontinence associated with amisulpride ${ }^{30)}$ and aripiprazole $^{31)}$ has also been reported. Here, we report a case of urinary incontinence as an adverse effect of paliperidone palmitate use for maintenance therapy in a patient with schizophrenia.

\section{CASE}

The patient was a 26 year-old, single woman with schizophrenia. She was diagnosed 5 years ago, in 2006, while she was a college student, and has always lived with her father and mother. Her first symptoms became evident when she was a freshman at college. She felt that she was neither liked nor cared for and was even harmed by some of her classmates. On several occasions, she got angry with and screamed at her friends for no obvious reasons. Sometimes, she spoke non-sense and behaved without any logical context. She claimed that her phone calls were being tapped and felt that she had always been mocked by people around her. She also claimed to have a sibling while she was actually the only child in her family.

After she was diagnosed with disorganized schizophrenia, she was hospitalized and treated with aripiprazole $(30 \mathrm{mg})$ daily. This treatment slightly improved her condition, and she was discharged to be followed-up routinely at an outpatient department, until the year of 2009. Then, however, she refused to go back to her daily routine and stopped taking her medication. After nearly 2-years of no treatment, her family members brought her to our outpatient clinic in the beginning of 2011, with severe positive symptoms including strange behaviors and bizarre talking.

We confirmed the previous diagnosis of disorganized schizophrenia and started oral paliperidone, by planning to switch into paliperidone palmitate soon, to prevent from non-compliance. Intramuscular depot paliperidone palmitate was started in February 2011 as follows: $150 \mathrm{mg}$ on the first day, $100 \mathrm{mg}$ on the eighth day and then $75 \mathrm{mg}$ monthly. A year later, in March 2012, the maintenance dosage was re-adjusted to $50 \mathrm{mg}$ monthly. Since then, she was followed-up at our outpatient clinic, and no exacerbation was noted. Her only complaint was mild dizziness when standing up, especially in the morning. The patient's condition was continuously monitored using various clinical scales. Changes in the scores for these scales are summarized in Table 1.

Her general medical condition has been otherwise normal except for the previously diagnosed polycystic ovary syndrome. She gained $7 \mathrm{~kg}$ since the beginning of the paliperidone palmitate treatment ( $73 \mathrm{~kg}$ vs. $80 \mathrm{~kg}$ ).

While reviewing our notes on her previous visits, we noticed a somewhat indistinct complaint; She had been experiencing some genitourinary symptoms for some time. She required treatment for vaginal candidiasis in September 2012. Although she tended to associate her complaints with this particular event, we realized that she had urinary incontinence, based on her description of physical properties of the discharged fluid, which she possibly misinterpreted as coming from vagina. Detailed examination of her clinical history revealed that the symptoms of urinary incontinence had actually first appeared just after the initial paliperidone palmitate treatment. Routine biochemical examination, complete blood count assessment, urinalysis, pelvic ultrasound examination as well as a comprehensive assessment at our urology department by using urethrocystography and uroflowmetry, showed no evidence of any other potential causes of

Table 1. Temporal changes of the scores in the clinical scales during the follow-up period

\begin{tabular}{lrrrr}
\hline & Admission & $\begin{array}{c}\text { 6th } \\
\text { month }\end{array}$ & $\begin{array}{r}\text { 12th } \\
\text { month }\end{array}$ & Current \\
\hline PANSS & 119 & 44 & 43 & 40 \\
$\quad$ Total & 31 & 9 & 9 & 9 \\
Positive subscale & 36 & 12 & 12 & 11 \\
Negative subscale & 52 & 23 & 22 & 20 \\
General psychopathology & & & & \\
$\quad$ subscale & & & & \\
CGI & 5 & 3 & 3 & 2 \\
CGI-S & NA & 2 & 2 & 1 \\
CGI-I & 40 & 70 & 75 & 80 \\
PSP & 0 & 0 & 0 & 0 \\
ESRS & & & & \\
\hline
\end{tabular}

PANSS, positive and negative symptoms scale; $\mathrm{CGI}$, clinical global impression; CGI-S, CGl-severity scale; CGI-I, CGI-improvement scale; PSP, personal and social performance; ESRS, extrapyramidal symptom rating scale; NA, not applicable. 
incontinence. She had no history of childhood enuresis or incontinence before paliperidone palmitate treatment. She also had no family history of incontinence. After discussing the side effect of the treatment with the patient and her family, we added treatment for incontinence. She was administered oral oxybutynin hydrochloride $(15 \mathrm{mg} /$ day $)$ for 3 months, and then switched to solifenacin succinate (5 $\mathrm{mg} /$ day) due to persistence of incontinence. On the second day of solifenacin treatment, she reported that her symptoms had resolved.

The patient's treatment then included paliperidone palmitate $(50 \mathrm{mg} / \mathrm{month})$ and solifenacin succinate $(5$ $\mathrm{mg}$ /day). After a year of treatment with this combination, solifenacin succinate was stopped. Since then, she has shown no signs of incontinence and is currently being continued with only paliperidone palmitate $(50 \mathrm{mg} / \mathrm{month})$, without any intervening psychotic episodes.

\section{DISCUSSION}

We encountered a patient with schizophrenia who developed urinary incontinence after starting paliperidone palmitate treatment. The incontinence was well managed by solifenacin succinate treatment. Although antipsychoticinduced urinary incontinence is believed to be more common than reported ${ }^{29,32)}$ and paliperidone has been suspected to cause urinary incontinence, to our knowledge, this is the first report of urinary incontinence induced by paliperidone palmitate, a slow-releasing and long-acting depot form of the atypical antipsychotic paliperidone.

Similar to regulation of micturition, regulation of continence involves a complex network of neural circuits in which several neurotransmitters like dopamine, serotonin, and some endorphins play important roles. In this context, enuresis must be differentiated from incontinence. During enuresis, all neuromuscular reflexes and functions are within the normal limits, and the main problem is the inappropriate timing of voiding. ${ }^{29)}$ Incontinence, on the other hand, involves involuntary loss of urine due to bladder over-reactivity, weakness of the bladder sphincter, or any incomplete bladder emptying situations.

Although common, drug-induced urinary incontinence is not well understood. The bladder is filled and emptied several times a day, and various neurotransmitter pathways are involved in controlling the lower urinary tract. These pathways can be targeted by most antipsychotic drugs, via binding to receptors for neurotransmitters such as serotonin, dopamine, acetylcholine, and adrenaline. ${ }^{29)}$

Some drugs might induce stress incontinence by antag- onizing $\alpha 1$-adrenoceptors ${ }^{33,34)}$ or nicotinic receptors. Urgency incontinence, which affects both genders, can be induced by the antagonism of $\beta 3$-adrenoceptors or agonism of muscarinic receptors. Conversely, overflow urinary incontinence is believed to be related to muscarinic receptors blocking, which explains incontinence induced by antipsychotics with antimuscarinic properties ${ }^{35)}$ as well as that included by blockade of pudendal reflexes via antagonism of 5-HT2 or 5-HT3 ${ }^{36)}$ or activation of neuronal 5-HT4 receptors in the detrusor muscle. ${ }^{37)}$

Based on these previous findings, we can hypothesize that the antagonistic effect of paliperidone palmitate on the 5-HT2A and $\alpha 1$ receptors in the detrusor muscle and internal bladder sphincter, respectively, might have contributed to incontinence in our case, though it had no noticeable anticholinergic effects.

In daily practice, the simplest management strategies for preventing incontinence, as a side effect, are reducing the antipsychotic dose, whenever possible, or the proportion of the daily dose given at night. Other measures such as avoiding excess fluid intake in the evening, avoiding caffeine and alcohol consumption, and emptying the bladder before sleeping can also be helpful. ${ }^{29)}$

Pharmacological management should be considered if there is a risk of cessation of the antipsychotic medicine or any decline in patient compliance; the pharmacological agents may include amitriptyline, desmopressin, ephedrine, and anticholinergics such as oxybutynin and trihexyphenidyl. ${ }^{31,38-40)}$ Some anticholinergic agents are regularly used to ease the urgency of urinary incontinence in clinical practice. In our case, we observed a substantial benefit after using the anticholinergic agent solifenacin, which is a competitive inhibitor of muscarinic M3 receptor. ${ }^{41)}$

In summary, we detected urinary incontinence only after we thoroughly examined all the possible side effects of the antipsychotic medication. Similar to previous publications, we found that urinary incontinence had developed long before the patient complained of it since she misinterpreted the symptoms to be vaginal discharge. We also noted that she seemed somewhat embarrassed while talking about this complains, which may further explain the delay in seeking a remedy after emergence of the symptoms. Another possible cause for the delay might be related to the thought disorder, in our case. As the thought disorder improved by treatment, she then realized the side effects, and felt well-enough to speak up to the physician. In our case, the most important factor that helped us detect the urinary incontinence was a systematic investigation 
for any adverse effect. Therefore, we recommend that the follow-up routines for patients receiving antipsychotic treatments include a form for standardized screening for all possible adverse effects.

\section{REFERENCES}

1. Pandina GJ, Lindenmayer JP, Lull J, Lim P, Gopal S, Herben $\mathrm{V}$, et al. A randomized, placebo-controlled study to assess the efficacy and safety of 3 doses of paliperidone palmitate in adults with acutely exacerbated schizophrenia. J Clin Psychopharmacol 2010;30:235-244.

2. Dolder C, Nelson M, Deyo Z. Paliperidone for schizophrenia. Am J Health Syst Pharm 2008;65:403-413.

3. Bishara D. Once-monthly paliperidone injection for the treatment of schizophrenia. Neuropsychiatr Dis Treat 2010; 6:561-572.

4. Leysen JE, Janssen PM, Megens AA, Schotte A. Risperidone: a novel antipsychotic with balanced serotonin-dopamine antagonism, receptor occupancy profile, and pharmacologic activity. J Clin Psychiatry 1994;55 Suppl:5-12.

5. Schotte A, Janssen PF, Gommeren W, Luyten WH, Van Gompel P, Lesage AS, et al. Risperidone compared with new and reference antipsychotic drugs: in vitro and in vivo receptor binding. Psychopharmacology (Berl) 1996;124:57-73.

6. van Beijsterveldt LE, Geerts RJ, Leysen JE, Megens AA, Van den Eynde HM, Meuldermans WE, et al. Regional brain distribution of risperidone and its active metabolite 9-hydroxy-risperidone in the rat. Psychopharmacology (Berl) 1994; 114:53-62.

7. Kramer M, Litman R, Hough D, Lane R, Lim P, Liu Y, et al. Paliperidone palmitate, a potential long-acting treatment for patients with schizophrenia. Results of a randomized, double-blind, placebo-controlled efficacy and safety study. Int J Neuropsychopharmacol 2010;13:635-647.

8. Samtani MN, Vermeulen A, Stuyckens K. Population pharmacokinetics of intramuscular paliperidone palmitate in patients with schizophrenia: a novel once-monthly, long-acting formulation of an atypical antipsychotic. Clin Pharmacokinet 2009;48:585-600.

9. Sedky K, Nazir R, Lindenmayer JP, Lippmann S. Paliperidonepalmitate: once-monthly treatment option for schizophrenia. Current Psychiatry (Online) 2010;9:48-50.

10. Gopal S, Vijapurkar U, Lim P, Morozova M, Eerdekens M, Hough D. A 52-week open-label study of the safety and tolerability of paliperidone palmitate in patients with schizophrenia. J Psychopharmacol 2011;25:685-697.

11. Nasrallah HA, Gopal S, Gassmann-Mayer C, Quiroz JA, Lim P, Eerdekens M, et al. A controlled, evidence-based trial of paliperidone palmitate, a long-acting injectable antipsychotic, in schizophrenia. Neuropsychopharmacology 2010;35:2072-2082.

12. Hough D, Gopal S, Vijapurkar U, Lim P, Morozova M, Eerdekens M. Paliperidone palmitate maintenance treatment in delaying the time-to-relapse in patients with schizophrenia: a randomized, double-blind, placebo-controlled study. Schizophr Res 2010;116:107-117.

13. Gopal S, Pandina G, Lane R, Nuamah I, Remmerie B, Coppola $\mathrm{D}$, et al. A Post-hoc comparison of paliperidone palmitate to oral risperidone during initiation of long-acting risperidone injection in patients with acute schizophrenia. Innov Clin Neurosci 2011;8:26-33.

14. Fleischhacker WW. Second-generation antipsychotic long- acting injections: systematic review. Br J Psychiatry Suppl 2009;52:S29-S36.

15. Citrome L. Paliperidone palmitate - review of the efficacy, safety and cost of a new second-generation depot antipsychotic medication. Int J Clin Pract 2010;64:216-239.

16. Coppola D, Liu Y, Gopal S, Remmerie B, Samtani MN, Hough DW, et al. A one-year prospective study of the safety, tolerability and pharmacokinetics of the highest available dose of paliperidone palmitate in patients with schizophrenia. BMC Psychiatry 2012;12:26.

17. Bossie CA, Sliwa JK, Ma YW, Fu DJ, Alphs L. Onset of efficacy and tolerability following the initiation dosing of long-acting paliperidone palmitate: post-hoc analyses of a randomized, double-blind clinical trial. BMC Psychiatry 2011;11:79.

18. Pandina G, Lane R, Gopal S, Gassmann-Mayer C, Hough $\mathrm{D}$, Remmerie $\mathrm{B}$, et al. A double-blind study of paliperidone palmitate and risperidone long-acting injectable in adults with schizophrenia. Prog Neuropsychopharmacol Biol Psychiatry 2011;35:218-226.

19. Nussbaum AM, Stroup TS. Paliperidone palmitate for schizophrenia. Schizophr Bull 2012;38:1124-1127.

20. Kantrowitz J, Citrome L. Paliperidone: the evidence of its therapeutic value in schizophrenia. Core Evid 2008;2:261-271.

21. Pani L, Marchese G. Expected clinical benefits of paliperidone extended-release formulation when compared with risperidone immediate-release. Expert Opin Drug Deliv 2009;6:319-331.

22. Clark N. Conventional antipsychotic and clozapine-induced urinary incontinence. JCPNP 2003;2:1-8.

23. Ambrosini PJ, Nurnberg HG. Enuresis and incontinence occurring with neuroleptics. Am J Psychiatry 1980;137: 1278-1279.

24. Shapiro AK. Pimozide-induced enuresis. Am J Psychiatry 1981;138:123-124.

25. Kiruluta HG, Andrews K. Urinary incontinence secondary to drugs. Urology 1983;22:88-90.

26. Ambrosini PJ. A pharmacological paradigm for urinary incontinence and enuresis. J Clin Psychopharmacol 1984;4: 247-253.

27. Harrison-Woolrych M, Skegg K, Ashton J, Herbison P, Skegg DC. Nocturnal enuresis in patients taking clozapine, risperidone, olanzapine and quetiapine: comparative cohort study. Br J Psychiatry 2011;199:140-144.

28. Barnes TR, Drake MJ, Paton C. Nocturnal enuresis with antipsychotic medication. Br J Psychiatry 2012;200:7-9.

29. Mendhekar D, Lohia D. Urinary incontinence associated with amisulpride. World J Biol Psychiatry 2009;10:1045-1046.

30. Bozkurt H, Abalı O. Aripiprazole-induced enuresis in a child with autistic disorder. Arch Neuropsychiatry 2011;48:164-166.

31. Vera PL, Miranda-Sousa A, Nadelhaft I. Effects of two atypical neuroleptics, olanzapine and risperidone, on the function of the urinary bladder and the external urethral sphincter in anesthetized rats. BMC Pharmacol 2001;1:4.

32. Fuller MA, Borovicka MC, Jaskiw GE, Simon MR, Kwon $\mathrm{K}$, Konicki PE. Clozapine-induced urinary incontinence: incidence and treatment with ephedrine. J Clin Psychiatry 1996;57:514-518.

33. Mendhekar DN, Andrade C. Risperidone-related reversal of primary enuresis: an unusual case report. World J Biol Psychiatry 2010;11:514-515.

34. Aronowitz JS, Safferman AZ, Lieberman JA. Management of clozapine-induced enuresis. Am J Psychiatry 1995;152:472.

35. Kantrowitz JT, Srihari VH, Tek C. Three cases of risperidoneinduced enuresis. Schizophr Res 2006;84:174-175. 
36. Tonini M, Candura SM. 5-HT4 receptor agonists and bladder disorders. Trends Pharmacol Sci 1996;17:314-316.

37. Steingard S. Use of desmopressin to treat clozapine-induced nocturnal enuresis. J Clin Psychiatry 1994;55:315-316.

38. Poyurovsky M, Modai I, Weizman A. Trihexyphenidyl as a possible therapeutic option in clozapine-induced nocturnal enuresis. Int Clin Psychopharmacol 1996;11:61-63.
39. Lurie SN, Hosmer C. Oxybutynin and intranasal desmopressin for clozapine-induced urinary incontinence. J Clin Psychiatry 1997;58:404.

40. Aggarwal A, Garg A, Jiloha RC. Trihexyphenidyl (benzhexol) in clozapine-induced nocturnal enuresis and sialorrhea. Indian J Med Sci 2009;63:470-471.

41. Kreder KJ. Solifenacin. Urol Clin North Am 2006;33:483-490. 